\title{
Allelopathy of aqueous extracts of Paubrasilia echinata (Lam.) Gagnon and H.C. Lima and G.P Lewis in lettuce seed germination
}

\author{
Alelopatia de extratos aquosos de Paubrasilia echinata ( Lam. ) Gagnon e H. C. \\ Lima e G. P. Lewis na germinação de sementes de alface
}

\section{Wellma Peclicya Silva da PAZ ${ }^{1}$; Maria Aliete Bezerra Lima MACHADO²; Kenia Almeida Diniz ALBUQUERQUE ${ }^{3}$}

1. Universidade Federal de Alagoas - Campus Arapiraca - Graduação em Ciências Biológicas - Licenciatura. Email: wellmapeclicya@ hotmail.com; 2. Universidade Federal de Alagoas Campus Arapiraca - Professora Doutora Associada I do Curso de Ciências Biológicas - Licenciatura. Email: maria.aliete@arapiraca.ufal.br; 3. Universidade Federal de Alagoas - Campus Arapiraca - Professora Doutora Associada II do Curso de Agronomia. Email: kenia.albuqerque@arapiraca.ufal.br

Email do autor principal: wellmapeclicya@hotmail.com

Recebido em outubro e aceito em dezembro 2020.

Resumo - O pau-brasil é uma espécie nativa ameaçada de extinção com potencial para uso em programas de reflorestamento, porém, há pouca informação sobre seu efeito alelopático na germinação de sementes de outras espécies. Sendo assim, objetivou-se com esse trabalho avaliar o efeito alelopático de extratos aquosos de Paubrasilia echinata Lam. Gagnon, H.C.Lima \& G.P.Lewis. na germinação de sementes de alface, visando a sua utilização em programas de reflorestamento. Amostras de folhas frescas e secas foram trituradas em liquidificador, acrescentando-se, posteriormente, $400 \mathrm{~mL}$ de água destilada e, após 10 minutos, as soluções foram filtradas. A partir desses extratos brutos, foram feitas diluições em água destilada e obteve-se os seguintes tratamentos: $0 \%, 25 \%, 50 \%, 75 \%$ e $100 \%$ dos extratos de folhas frescas e secas. Foi feito o teste de germinação das sementes de alface embebidas nos extratos, seguindo as recomendações das Regras para Análise de Sementes (RAS). Foi feita a contagem diária, avaliando-se o índice de velocidade de germinação, a velocidade de germinação e a porcentagem de germinação, sendo consideradas germinadas as sementes com $2 \mathrm{~mm}$ de comprimento de radícula. As análises estatísticas foram realizadas usando o programa GRAPHPAD PRISM. Concluiu-se que $P$. echinata exerce efeito alelopático na germinação de sementes de alface. $\mathrm{O}$ uso de $P$. echinata em programas de reflorestamento deve ser criterioso, com a adoção de medidas que minimizem a alelopatia em plantas circunvizinhas.

Palavras-chave: Aleloquímicos. Espécies nativas. Pau-brasil.

Abstract - Brazilwood is an endangered native species with potential for use in reforestation programs, however, there is little information about its allelopathic effect on the germination of seeds of other species. Thus, the objective of this work was to evaluate the allelopathic effect of aqueous extracts of Paubrasilia echinata L. on the germination of lettuce seeds, aiming at their use in reforestation programs. Samples of fresh and dried leaves were crushed 
in a blender, subsequently adding $400 \mathrm{~mL}$ of distilled water and, after 10 minutes, the solutions were filtered. From these crude extracts, dilutions were made in distilled water and the following treatments were obtained: $0 \%, 25 \%, 50 \%, 75 \%$ and $100 \%$ of the fresh and dried leaf extracts. The germination test of lettuce seeds embedded in the extracts was carried out, following the recommendations of the Rules for Seed Analysis (RAS). The daily count was made, evaluating the germination speed index the germination speed and the germination percentage, considering the seeds with germination. $2 \mathrm{~mm}$ radicle length. Statistical analyzes were performed using the GRAPHPAD PRISM program. It was concluded that $P$. echinata has an allelopathic effect on the germination of lettuce seeds. The use of $P$. echinata in reforestation programs must be judicious, with the adoption of measures that minimize allelopathy in surrounding plants.

Keywords: Allelochemicals. Native species. Brazilwood.

\section{Introdução}

Alelopatia foi um termo utilizado pela primeira vez por Molisch, no ano de 1937, o qual o utilizou para caracterizar interações bioquímicas entre plantas, podendo ser incluídos microrganismos. Essas interações podem ser decorrentes da ação de substâncias químicas, chamadas de aleloquímicos, por meio de vias metabólicas das plantas e liberadas no meio ambiente (RICE,1984).

Há uma grande diversidade e quantidade de compostos aleloquímicos. Dentre eles destacam-se: taninos, glicosídeos, cianogênicos, alcalóides, sesquiterpenos, flavonóides, ácidos fenólicos, entre outros (RIZVIet al., 1992 apud MARASCHIN-SILVA; AQUILA, 2006). Essas substâncias aleloquímicas podem ser encontradas em várias partes da planta, como folhas, flores, frutos, caules, raízes e sementes (MIRO et al., 1998). Segundo Rodrigues; Rodrigues; Reis (1992), essas substâncias podem ser inibidoras da germinação ou do crescimento, pelo fato de poderem interferir na divisão celular, na permeabilidade de membranas, na ativação de enzimas e na produção de hormônios nas plantas.

Todas as plantas produzem metabólitos secundários, sendo, portanto, importante a realização de estudos aprofundados em busca do conhecimento da interferência destas substâncias na germinação e crescimento de plantas circunvizinhas, expostas a diversos fatores ambientais. Contudo, a observação dessa possível interferência torna-se difícil de ser observada no campo, pois não há como distinguir se o dano causado foi devido aos compostos alelopáticos ou aos fatores a que a planta está exposta (BRITO, 2010).

Para realização de trabalhos voltados a investigação de potenciais alelopáticos é viável utilizar a alternativa de fazer estudos em laboratório, com a utilização de bioensaios, pois há a obtenção de dados com maior precisão, já que é possível controlar alguns fatores essenciais à vida da planta na natureza, tais como, luminosidade, umidade e pragas (ALVES et al.,1992). Segundo Inderjit e Dashini (1995), deve-se dar preferência em experimentos com alelopatia, a água como solvente, pois assemelha-se ao que ocorre na natureza. Quando se busca resultados de significado ecológico, é muito importante extrações e procedimento para testes que 
simulem processos naturais, assim têm-se dados mais significativos e verídicos (STOWE; KIL,1983).

Ainda há uma carência de estudos sobre o potencial alelopático de espécies nativas. Pelo fato do pau-brasil ter uma importância histórica e por ser uma espécie nativa, ameaçada de extinção, justifica-se a investigação do potencial alelopático dessa espécie.

Partindo da hipótese de que os extratos de Paubrasilia echinata ( Lam. ) Gagnon e HCLima e GPLewis (Fabaceae-Caesalpinioidae) (pau-brasil) possuem atividade alelopática, objetivou-se com esse trabalho avaliar o efeito alelopático desses extratos na germinação de sementes de Lactuca sativa L. (Asteraceae) (alface), visando a sua utilização em projetos de recuperação de áreas degradadas da Bacia Hidrográfica do Rio São Francisco.

\section{Material e Métodos}

O experimento foi conduzido nos Laboratórios de Química e Entomologia da Universidade Federal de Alagoas (UFAL), Campus Arapiraca. Nas proximidades do Campus foram coletados e prensados ramos com folhas, flores e frutos de Paubrasilia echinata L. Os mesmos foram colocados em estufa de secagem por três dias a uma temperatura de $70{ }^{\circ} \mathrm{C}$, sendo posterior herborizados, conforme normas técnicas de herbário (Mori et al.,1989). A identificação foi realizada no Herbário MAC do Instituto do Meio Ambiente do Estado de Alagoas e a exsicata foi depositada neste herbário sob número 55213.

Uma amostra de 100 gramas de folhas frescas foi utilizada para o preparo do extrato aquoso. As folhas foram selecionadas, lavadas em água corrente e água destilada e postas para secar a temperatura ambiente. Depois de secas, as folhas foram trituradas em liquidificador, previamente esterilizado com álcool, sem utilizar água. Logo após este procedimento, o material foi colocado em um Becker e acrescentou-se $400 \mathrm{~mL}$ de água destilada. Após 10 minutos, a solução foi filtrada em papel filtro, acondicionada em vidros translúcidos e guardada em geladeira.

Para a obtenção do extrato com folhas secas, foram coletadas mais 100 gramas de folhas frescas, prensadas e colocadas em estufa de secagem por três dias a $50{ }^{\circ} \mathrm{C}$. Após a secagem, o procedimento utilizado foi o mesmo descrito acima.

A partir dos extratos brutos, foram feitas diluições em água destilada, obtendo-se as concentrações de $25 \%, 50 \%$ e $75 \%$ do extrato. $\mathrm{O}$ pH de cada extrato foi medido utilizando-se um pHmetro (pH-100 Labmeter).

Para a montagem dos bioensaios foram utilizadas quatro repetições de 25 sementes de alface semeadas em caixas acrílicas tipo Gerbox, contendo duas folhas de papel mata borrão umedecidas com $5 \mathrm{~mL}$ de água destilada (controle), $100 \%$ extrato bruto e as diluições (25\%, $50 \%$ e $75 \%$ ), tanto do extrato de folhas frescas quanto do extrato de folhas secas. As caixas foram embaladas em plástico filme e levadas para a câmara de germinação tipo B.O.D. com fotoperíodo de 12 horas e temperatura de $25^{\circ} \mathrm{C}$. Foi feita a contagem diária, avaliando-se o índice de velocidade de germinação (MAGUIRE, 1962), a velocidade de germinação (EDMOND; DRAPALLA, 1958 apud FERREIRA; BORGUETTI, 2004) e a porcentagem de germinação, conforme as Regras para Análise de Sementes (BRASIL, 2009), sendo consideradas germinadas as sementes com $2 \mathrm{~mm}$ de comprimento de radícula.

Foi utilizado o delineamento inteiramente casualizado com dois fatores (folhas frescas e folhas secas), cinco tratamentos $(0 \%, 25 \%, 50 \%, 75 \%$ e $100 \%$ do extrato) e quatro 
repetições. As médias foram analisadas pelo teste de Tukey $(p \leq 0.05)$ com auxílio do programa GRAPHPAD PRISM.

\section{Resultados e Discussão}

Os valores do $\mathrm{pH}$ registrados para os extratos de $P$. echinata nas concentrações de $100 \%, 75 \%, 50 \%, 25 \%$ e $0 \%$ foram, respectivamente, 6,$3 ; 6,5 ; 6,4 ; 6,4$ e 6,9 , sendo classificados como adequados para a germinação das sementes em experimentos de laboratório. De acordo com Larcher (2000), valores de pH entre 6,0 e 7,5 favorecem os processos bioquímicos e a nutrição vegetal.

As sementes de alface começaram a germinar após $48 \mathrm{~h}$ de incubação. A porcentagem de germinação para as sementes embebidas em extrato de folhas frescas de pau-brasil, nas concentrações de $100 \%, 75 \%, 50 \%$ e $25 \%$ foi, respectivamente, $62 \%, 87 \%, 81 \%$ e $93 \%$. Já o tratamento controle a porcentagem de germinação foi de $91 \%$. Na figura 1 observa-se que apenas o tratamento com extrato de $100 \%$ de folhas frescas de $P$. echinata teve diferença significativa em relação ao controle, o que demonstra um possível efeito alelopático provocado pelo uso do extrato nessa concentração. Rezende et al. (2004) estudando a composição química de folhas de pau-brasil verificaram que a classe de metabólitos mais bem representada foi a dos compostos fenólicos e, segundo Rice (1984) e Bewley e Black (1994), esses metabólitos secundários estão entre os que possuem maior atividade alelopática.

Figura 1- Porcentagem de germinação de sementes de Lactuca sativa embebidas em extratos aquosos de folhas frescas de $P$. echinata.

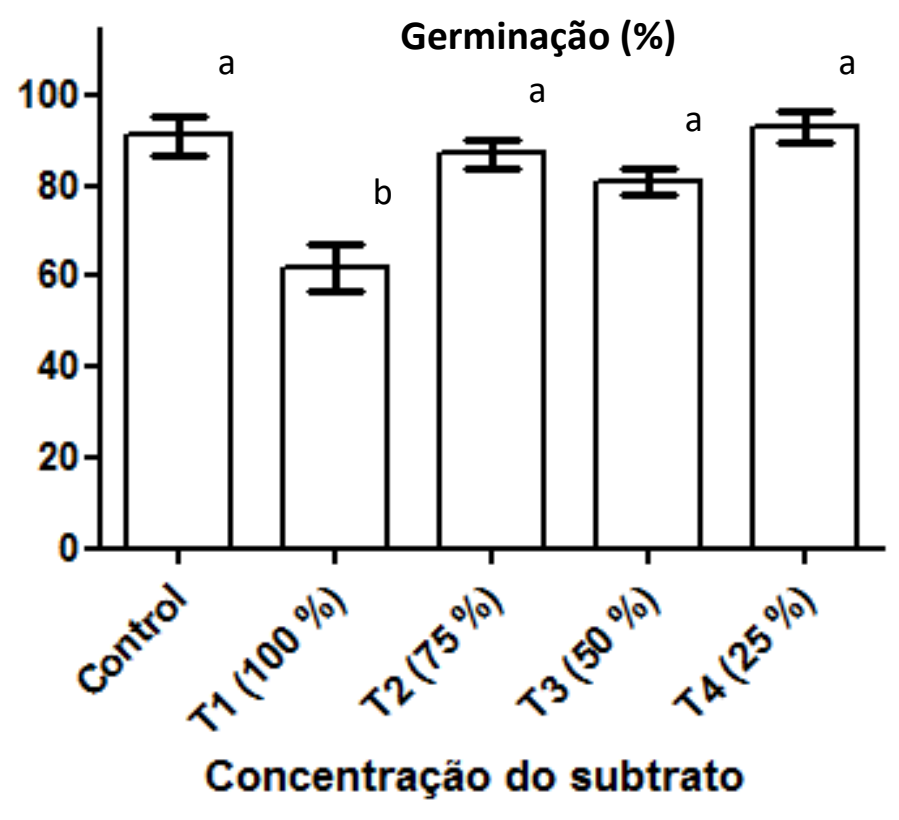


Souza et al. (2007), estudando a espécie Schinus terebinthifolius na germinação de sementes de alface verificou que o extrato na concentração de $100 \%$ interferiu significativamente na porcentagem de germinação, apresentando efeito alelopático. Ribeiro et al. (2009), também encontraram resultados semelhantes quando utilizaram extratos aquosos de Crinum americanum na embebição de sementes de alface.

Ao se utilizar o extrato obtido de folhas secas de $P$. echinata nas concentrações de $100 \%, 75 \%, 50 \%$ e $25 \%$ obteve-se $1 \%, 13 \%, 20 \%$ e $63 \%$ de germinação, respectivamente. Já a porcentagem de germinação para o tratamento controle foi de $98 \%$. Como pode ser observado na figura 2, houve diferença significativa em relação ao tratamento controle para todas as concentrações testadas do extrato, sendo que quanto mais concentrado o extrato, menor a porcentagem de germinação das sementes de alface. A desidratação pode alterar a concentração de compostos fenólicos nas folhas (HISTER, 2017). Em estudos realizados por Goetze e Thomé (2004), Jacobi e Ferreira (1991) e Fachinetto et al. (2007) foi evidenciada a maior concentração dos metabólitos secundários em material vegetal após o processo de secagem, potencializando os efeitos inibidores da germinação. De acordo com Rice (1984) e Rizvi e Rizvi, (1992) esses efeitos inibitórios incluem as alterações no metabolismo vegetal, o que afeta as características e a divisão das células, a absorção de nutrientes e a atividade respiratória e enzimática.

Figura 2 - Porcentagem de germinação de sementes de alface embebidas em extratos aquosos de folhas secas de $P$. echinata.

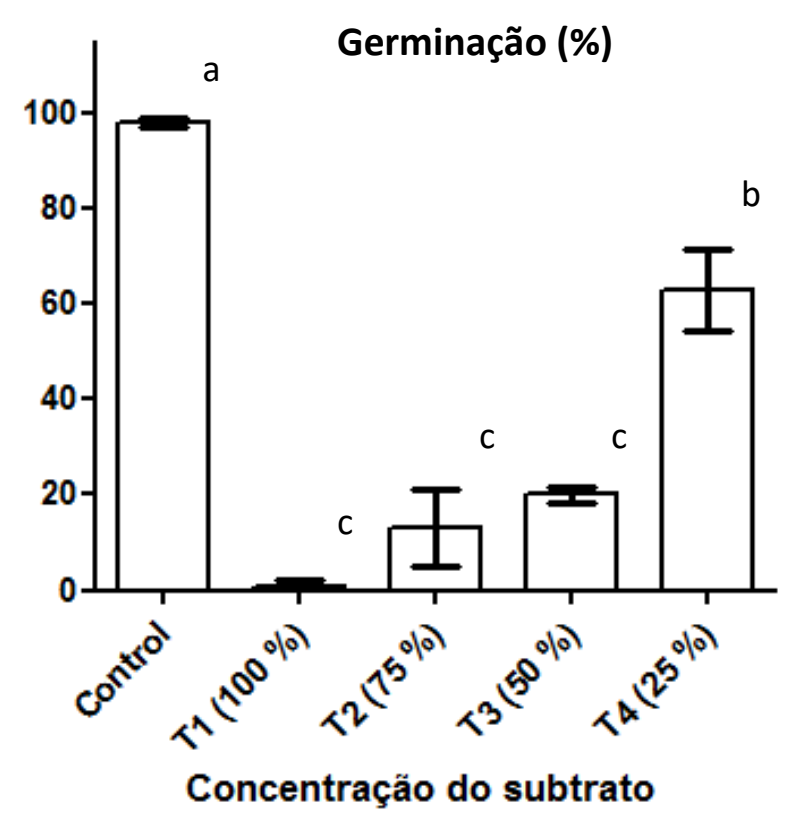

Azevedo e Souza (2009) analisaram extratos de Capparis jacobinae e encontraram resultados semelhantes, com todas as concentrações testadas diferindo do controle, principalmente nas maiores concentrações. Gusman et al. (2011) em pesquisas realizadas com extratos das espécies Bidens pilosa, Cyperus rotundus e Euphorbia heterophylla na 
germinação de sementes algumas hortaliças, como a alface, verificaram uma diminuição na germinação das sementes com o aumento das concentrações do extratos, diferentemente de Maraschin Silva e Aquila (2006) que verificaram que os extratos de Erythroxy lumargentinum, Luchea divaricata, Myrsine guianensis e Ocotea puberula não interferiram na germinação de sementes de alface.

Para a variável velocidade de germinação (VG) observou-se os resultados de 2,05 (controle), 2,80 (100\%), 2,54 (75\%), 2,44 (50\%) e 2,15 (25\%) quando as sementes foram embebidas em extrato de folhas frescas. $\mathrm{O}$ tratamento controle diferiu significativamente das concentrações de $100 \%, 75 \%$ e $50 \%$. Houve maior velocidade de germinação com o aumento da concentração do extrato de folhas frescas (Figura 3). Segundo Santana e Ranal (2000) a interpretação do resultado do VG é similar ao tempo médio de germinação, pois as fórmulas de cálculo são idênticas. Dessa forma, Ferreira e Borghetti (2004) interpretam que quanto menor o VG, maior o vigor da amostra de sementes. Sendo assim, com o aumento nas concentrações dos extratos houve uma diminuição no vigor das sementes, demonstrando a atividade alelopática dos extratos de folhas frescas de $P$. echinata.

Figura 3 - Velocidade de germinação de sementes de alface embebidas em extratos aquosos de folhas frescas de P. echinata.

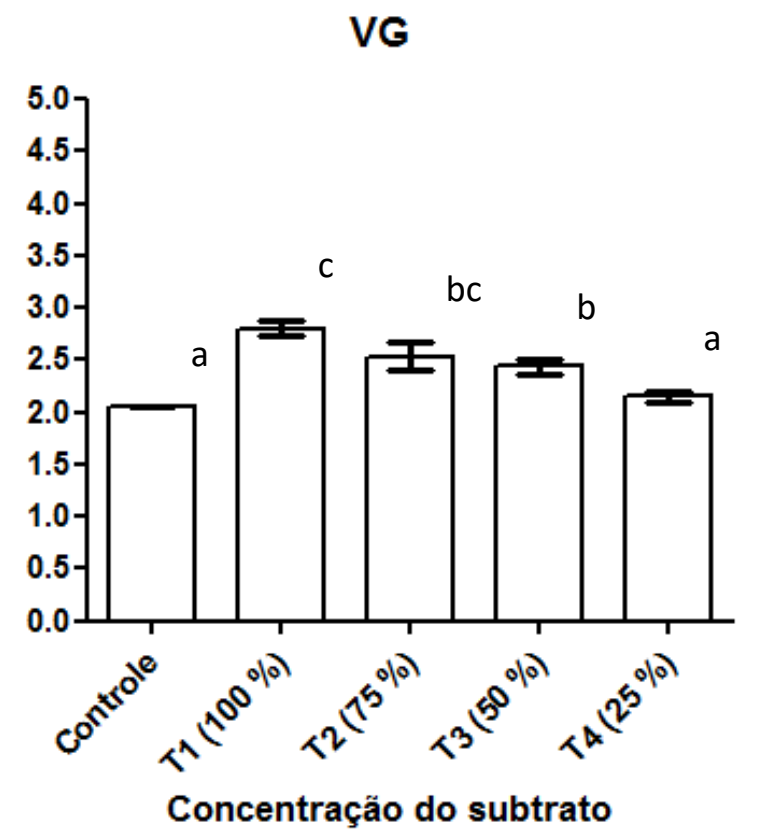

Fato semelhante também aconteceu com a embebição das sementes de alface em extratos de Crinum americanum, que também proporcionou aumento da velocidade de germinação com o aumento da concentração (RIBEIRO et al., 2009). Porém, Barreiro et al. (2005) observaram que extratos de barbatimão (Stryphnodendron adstringens) proporcionaram redução da velocidade de germinação com o aumento da concentração, assim como Gotze e Thomé (2004) com extratos de Nicotina tabacum e Eucalyptus grandis. 
Ao se utilizar o extrato de folhas secas de $P$. echinata a velocidade de germinação das sementes de alface foi de 2,24 (controle), 5,1 (100\%), 4,35 (75\%), 4,42 (50\%) e 2,9 (25\%), respectivamente. Houve diferença significativa entre o controle e todas as concentrações do extrato, sendo que quanto maior a concentração, maior o VG, conforme Figura 4.

Figura 4 - Velocidade de germinação de sementes de alface embebidas em extratos aquosos de folhas secas de $P$. echinata.

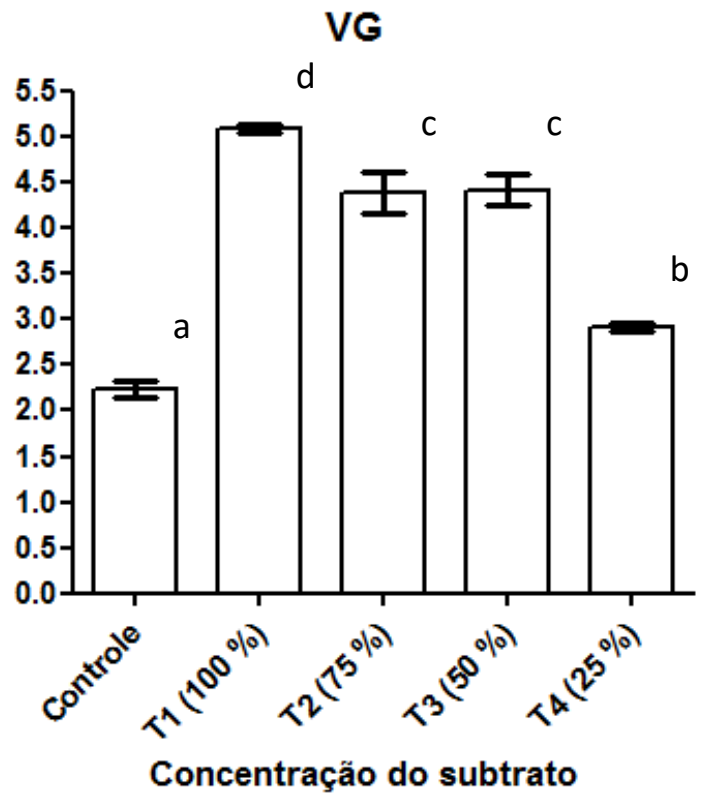

Ferreira et al. (2010) estudaram o efeito dos extratos de Mimosa caesalpiniae na germinação de sementes de Phaseolus lunatus e não encontraram diferenças significativas na velocidade de germinação, assim como Roger et al. (2007) com extratos de Acacia mangium em sementes de alface.

Os resultados encontrados para o índice de velocidade de germinação foram de 11,16 (controle), 5,92 (100\%), 9,09 (75\%), 8,86 (50\%) e 11 (25\%) quando as sementes foram embebidas em extrato aquoso de folhas frescas, sendo possível observar diferença significativa entre o tratamento controle e as concentrações de $100 \%$, $75 \%$ e $50 \%$, havendo uma diminuição do índice com o aumento da concentração do extrato (Figura 5). 
Figura 5 - Índice de velocidade de germinação de sementes de alface embebidas em extratos aquosos de folhas frescas de P. echinata.

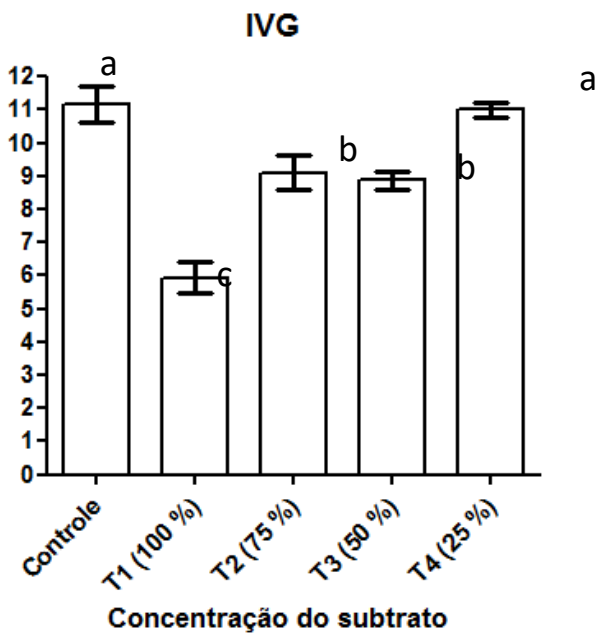

De acordo com Nakagawa (1999 apud FERREIRA; BORGHETTI, 2004), quanto maior o índice de velocidade de germinação maior o vigor das sementes. Sendo assim, podese afirmar que o uso do extrato de folhas frescas de $P$. echinata, nas maiores concentrações, provocou uma queda no vigor das sementes de alface.

Bonfim et al. (2011) afirmam que extratos de Melissa officinalis e Mentha villosa também reduziram o índice de velocidade de germinação de sementes de Plantago major. Para Alves et al. (2011) os extratos de Eclipta alba, Gomphrena globosa, Tabernemontana catharinensis e Tithonia diversifolia também interferiram negativamente no índice de velocidade de germinação de sementes de alface. Souza et al. (2007) também encontraram resultados semelhantes com os deste estudo nas maiores concentrações de extratos de Schinus terebinthifolius.

Para os extratos de folhas secas, os índices de velocidade de germinação encontrados foram de 10,31 (controle), 0,05 (100\%), 0,063 (75\%), 1,15 (50\%) e 6,08 (25\%), com diferença significativa entre o tratamento controle e todas as concentrações do extrato. Como pode ser observado na figura 6 , houve redução no índice à medida que se aumentou a concentração do extrato de folhas secas. Esse resultado salienta um possível aumento na concentração dos compostos fenólicos após o processo de secagem das folhas, pois ainda houve uma redução no IVG das sementes embebidas em extratos de folhas secas quando comparado aos das folhas frescas. 
Figura 6 - Índice de velocidade de germinação de sementes de alface embebidas em extratos aquosos de folhas secas de $P$. echinata.

\section{IVG}

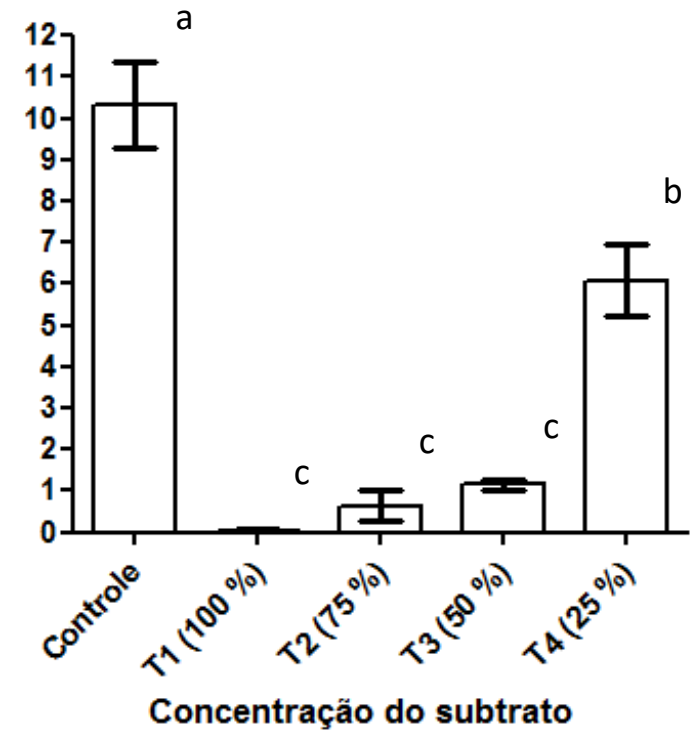

Rosado et al. (2009) quando analisaram o efeito alelopático de extratos aquosos de folhas de Ocimun basilicum na germinação de sementes de alface, verificaram diminuição no índice de velocidade de germinação com o aumento da concentração do extrato. Pelegrini e Cruz-Silva (2012) também encontraram resultados semelhantes com extratos de Coleus barbatus em sementes de alface.

\section{Conclusão}

P. echinata exerce efeito alelopático na germinação de sementes de alface, sendo esse efeito ainda mais drástico em extratos de folhas secas e nas maiores concentrações.

O uso de P. echinata em programas de recuperação de áreas degradadas da Bacia do Rio São Francisco deve ser criterioso, com a adoção de medidas que minimizem a alelopatia em plantas circunvizinhas.

\section{Conflito de interesses}

Os autores deste manuscrito não declararam conflitos de interesse. 


\section{Referências Bibliográficas}

ALVES, P.L.C.A.etal.Estudo das propriedades alelopáticas de espécies de Eucalyptusspp. e suapotencialidade no manejo de plantas daninhas. Relatório FINEP. Jaboticabal: FCAV, 273p, 1992.

ALVES, L.L.;etal.Atividadealelopática de extratos aquosos de plantas medicinais na germinação deLactuca sativa L. e Bidens pilosa L. Revista Brasileira Plantas Medicinais,v.13, n.3, p.328-336, Botucatu, 2011.

AZEVEDO, L. N.; SOUZA, K.M.O. Potencial Alelopático dos extratos de capparisjacobinaemoric na germinação de lactuca sativa. IN: JORNADA DE ENSINO, PESQUISA E EXTENÇÃO-JEPEX,9, 2009, Anais... Recife. Disponível em <http://www.eventosufrpe.com.br/eventosufrpe/jepex2009/cd/resumos/R1064-1.pdf> Acesso em 03/12/2013.

BARREIRO, A. P., DELACHIAVE, M. E. A., SOUZA, F. S. Efeito alelopático de extratos de parte aérea de Barbatimão [ Stryphnodendron adstringens ( Mart.) Coville ] na germinação e desenvolvimento da plântula de pepino. Revista Brasileira de Plantas Medicinais, Botucatu, v. 8, n.1, p.4-8, 2005.

BEWLEY, J.D.; BLACK, M. Seeds: physiology of development and germination, 2. ed. New York: Plenum Press, 1994. 445p.

BONFIM,F.P.G et al. Potencial alelopático de extratos aquosos de Melissa officinalis L. e Mentha villosa L. na germinação e vigor de sementes de Plantago major L.. Revista Brasileira de Plantas Medicinais, Botucatu, v.13, especial, p.564-568, 2011.

BRASIL. Ministério da Agricultura e Reforma Agrária. Regras para análise de sementes. Brasília: SNDA/DNDV/CLAV, 399 p. 2009.

BRITO, I. C. A. Alelopatia de espécies arbóreas da caatinga na germinação e vigor de sementes de feijão macacar e de milho. 2010. 53f. Dissertação (Mestrado em Zootecnia SistemasAgrosilvipastoris no Semi-Árido). Universidade Federal de Campina Grande, Patos, PB, 2010.

FERREIRA, A. G.; BORGUETTI, F.Germinação:do básico ao aplicado. Porto Alegre: Artmed, 2004. 323 p.

FERREIRA, E. G. B. S. et al. Efeito alelopático do extrato aquoso de sabiá na germinação de sementes de fava. Revista Ciência Agronômica, v.41, n 3, p.463-467, 2010.

GOETZE, M.; THOMÉ, G. C. H. Efeito Alelopático de extratos de Nicotiana tabacum e Eucalyptus grandis sobre a germinação de três espécies de hortaliças. Revista brasileira de Agrociência, Santa Cruz do Sul, v. 10, n. 1, p. 43-50, 2004.

GUSMAN, G. S.; YAMAGUSHI, M. Q.; VESTENA, S. Potencial alelopático de extratos aquosos de Bidens pilosa L., Cyperus rotundus L. e Euphorbia heterophylla L.; Iheringia, Série Botânica, Porto Alegre, v. 66, n. 1, p. 87 - 98, 2011.

HISTER et al. Atividade antiproliferativa e determinação dos compostos fenólicos de extratos aquosos de amoreira-preta (Rubus sp.) pelo sistema teste in vivo de Allium cepa L. Revista Brasileira de Biociências, Porto Alegre, v. 15, n.1, p. 43-48, jan./mar. 2017.

INDERJIT, S; DAKSHINI, K.M.M.On laboratory bioassays in allelopathy. Botanical Review, Bronx, v.61, n.1, p.28-44, 1995.

JACOBI U. S.; FERREIRA A. G. Efeitos alelopáticos de Mimosa bimicronata (DC). sobre espécies cultivadas. Pesquisa Agropecuaria Brasileira. 26: p.935-943. 1991.

LARCHER, W. Ecofisiologia vegetal. São Carlos: Rima, 2000. 531p. 
MAGUIRE, J. D. Speed of germination-aid in selection evaluation for seedling emergence and vigour. Crop Science, Madison, v. 2, n. 2, p. 176-177; 1962.

MARASCHIN-SILVA, F.; AQÜILA, M. E. A. Potencial alelopático de espécies nativas na germinação e crescimento inicial de Lactuca sativa L. (Asteraceae), Acta Botânica Brasileira, Porto Alegre,v.20, n.1, p. 61-69, 2006.

MIRO, C.P.; FERREIRA, A.G.; ÁQUILA, M.E.A. Alelopatia de frutos de erva mate (Ilex paraguariensis) no desenvolvimento do milho. Pesquisa Agropecuária Brasileira, v.33, n.8,p.1261-1270, 1998.

MORI, S. A.; et al. Manual de Manejo do Herbário Fanerogâmico. Ilhéus: Centro de Pesquisa do Cacau, 1989.

PELEGRINI, L.L; CRUZ-SILVA, C,T,A. Variação sazonal na alelopatia de extratos aquosos de Coleus barbatus (A.) Benth. sobre a germinação e o desenvolvimento de Lactuca sativa L. Revista Brasileira Plantas Medicinais.,Botucatu, v.14, n.2, p.376-382, 2012.

REZENDE C. M.,et al. Constituintes químicos voláteis das flores e folhas do pau-brasil (Caesalpinia echinata, Lam.).Química Nova, Rio de Janeiro, v.27, n.3, p. 414-416, 2004.

RIBEIRO, J. P. N.;et al. Efeitos alelopáticos de extratos aquosos de Crinum americanum L.; Revista Brasileira de Botânica, v.32, n.1, p.183-188, 2009.

RICE, E.L. Allelopathy. 2.ed. New York: Academic Press, 422p,1984.

RODRIGUES, L.R.A; RODRIGUES, T.J.D; REIS, R.A. Alelopatia em plantas forrageiras. FUNEP,Jaboticabal, 68p. 1992.

ROGER, J. A.; ZANOTTI, R. F.; CRISTIANA, M. C. Potencial alelopático de Acaciamangiumsobre sementes de alface. In: CONGRESSO DE ECOLOGIA DO BRASIL, 8., 2007, Caxambu- MG. Anais...Caxambu, 2007. P. 1-2.

ROSADO, C. P. S. et al. Alelopatia do extrato aquoso e do óleo essencial de folhas do manjericão "Maria Bonita" na germinação de alface, tomate e melissa. Revista Brasileira de Plantas Medicinais, Botucatu, v.11, n.4, p.422-428, 2009.

SOUZA, C. S. M. et al. Alelopatia do extrato aquoso de folhas de aroeira na germinação de sementes de alface. Revista Verde de Agroecologia e Desenvolvimento Sustentável. Grupo Verde de Agricultura Alternativa (GVAA). Mossoró,v.2, n.2, p.96- 100, 2007.

STOWE, L.G.; KIL, B. The role of toxins in plant-plant interactions. In: KEELER,R.F.;TU, A.T. (Eds.). Handbook of natural toxins.New York: Marcel Dekker, v.1, p.707-741, 1983. 